\title{
Autonomous microgrid based parallel inverters using droop controller for improved power sharing
}

\author{
Siddaraj $^{1}$, Udaykumar R. Yaragatti ${ }^{2}$, Nagendrappa $\mathbf{H}^{3}$, Vikash Kumar Jhunjhunwala ${ }^{4}$ \\ ${ }^{1,4}$ Department of Electrical and Electronics Engineering, Manipal Institute of Technology, \\ Manipal Academy of Higher Education, Manipal, India \\ ${ }^{2,3}$ Department of Electrical and Electronics Engineering, National Institute of Technology Karnataka, \\ Surathkal, Mangaluru, India
}

\begin{tabular}{l}
\hline \hline Article Info \\
\hline Article history: \\
Received Apr 14, 2020 \\
Revised Jun 1, 2020 \\
Accepted Jul 3, 2020 \\
\hline
\end{tabular}

Keywords:

Droop controller Inverter analysis Microgrid Parallel inverters Voltage source inverter

\begin{abstract}
The existing microgrid has become a challenge to the sustainable energy source to provide a better quality of power to the consumer. To build a reliable and efficient microgrid, designing a droop controller for the microgrid is of utmost importance. In this paper, multiple voltage source inverters connected in parallel using an active power-frequency/reactive power-voltage droop scheme. The proposed method connected to two distributed generators local controllers, where each unit consists of a droop controller with an inner voltage-current controller and a virtual droop controller. By adding this controller to the microgrid reliability and load adaptability of an islanded system can be improved. This concept applied without any real-time communication to the microgrid. Thus, simulated using MATLAB/Simulink, the obtained results prove the effectiveness of the autonomous operation's microgrid model.
\end{abstract}

This is an open access article under the CC BY-SA license.

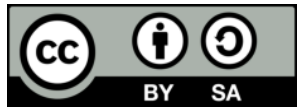

\section{Corresponding Author:}

Siddaraj,

Department of Electrical and Electronics Engineering,

Manipal Institute of Technology,

Manipal Academy of Higher Education,

Tiger Circle Road, Madhav Nagar, Manipal, Karnataka 576104, India.

Email: siddaraj.u@manipal.edu

\section{INTRODUCTION}

Microgrid based sustainable energy resources such as distributed generators (DG) sources, storage devices, and local loads are the future generating plants $[1,2]$. So the consumer can be able to produce, store, control, and manage apart from consuming the power [3]. Besides, the critical load is allowed to connect to the utility or autonomous mode for continuous operation [4]. The microgrid deals issues of power quality, so; it can have interaction between utility grid or other microgrids-integrated control strategies, which usually consist of primary, secondary, and tertiary controller [5].

The droop-based scheme is often used for the autonomous microgrid to control microgrid inverter when more than one DGs connected in parallel [6, 7]. Implementing the droop scheme allows DG inverters to share the load proportionally by adjusting the voltage and frequency as a parameter of the total power. Besides, each inverter uses local measurements. Likewise, to improve the effectiveness of the droop-based voltage source inverter (VSI), a virtual impedance control based scheme has been also adopted [8]. During islanded mode, the inverters should not overload. Inverters take the load change assurance by a proper control-based approach. The communication-based master-slave control method added to the microgrid, where DG sources are connected to a local bus or located nearby [9]. Besides, communication-based control makes the system 
costly and not reliable. Droop based approach, which uses local measurements by eliminating communication link, has been proposed [10]. In this work, by avoiding the former method, later method is adopted. In this paper, the proper load sharing purpose, the droop controller, is used in autonomous DG mode. The proposed control method for three-phase inverters, connected in parallel to the point of common coupling (PCC) buses through filter and coupling inductor. The presented controller maintains the frequency and voltage constant to achieve proportional load demand, excluding communication devices. Simulation work has done to test the effectiveness of the proposed controller under different conditions. The intended results show by using this controller in voltage, frequency regulation, and power-sharing.

The presented paper has the following main contributions:

- Each DGs VSI proposed with a droop controller to share the significant P and Q power with other DGs.

- Each VSI controller proposed with the current controller loop (CCL), voltage controller loop (VCL), and virtual impedance loop; thus, it was designed to reject high-frequency noise and damp the filter output, and improve power-sharing also eliminates circulating current.

- We are analyzing graphically step-by-step of direct (d) and quadrature (q)-axis VCL and CCL to decouple the disturbance, thus enhancing the VSI system's performance.

The paper prepared as follows: Section 1 contains the proposed controller in the microgrid. In section 2, the voltage source inverter modeling analyzed. A MATLAB/Simulink work and its results and discussion carried out in section 3. Section 4 concludes the work.

\section{THE MICROGRID ARCHITECTURE AND CONTROL METHODOLOGY}

A DGs VSI based three-phase microgrid and inverter controller, as shown in Figure 1. The simulation study has done to verify its robustness. The two VSIs connected to the nonlinear load through network lines. DG sources connected to the inverter's input. The related system parameters given in Table 1 . both VSIs have used the droop control method for maintaining frequency and bus voltages within permissible value during the load-generation balance. The VSIs rating is the same, so the droop gain also is chosen the same. The VSIs controller has a series-connected voltage and current loop [11]. The DG controller as follows:

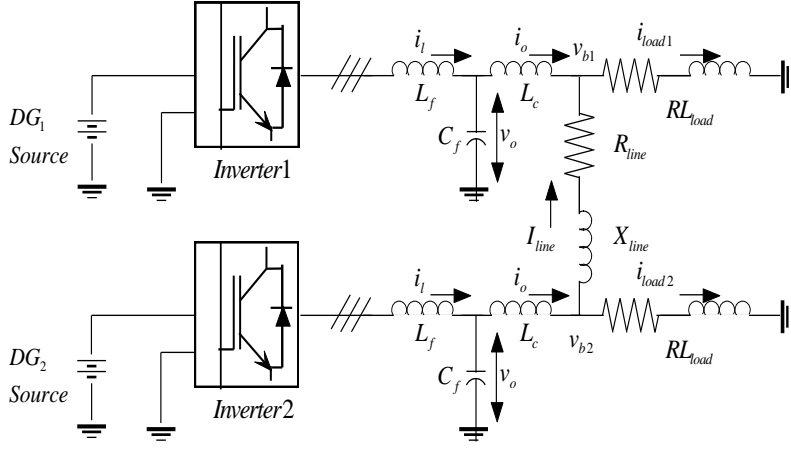

(a)

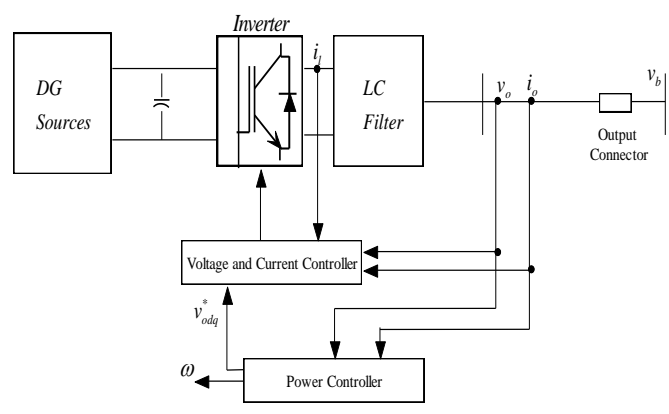

(b)

Figure 1. Distributed generators, (a) DGs VSI based microgrid block diagram, (b) Inverter controller block diagram

Table 1. System parameters

\begin{tabular}{llll}
\hline \multicolumn{1}{c}{ Parameters } & Value & \multicolumn{1}{c}{ Parameters } & Value \\
\hline DG1 & $10 \mathrm{~kW}$ & DG 2 & $10 \mathrm{~kW}$ \\
Inverter1 Rating & $12 \mathrm{KVA}$ & Inverter2 Rating & $12 \mathrm{KVA}$ \\
Inverter Switching Frequency $\left(f_{s}\right)$ & $8 \mathrm{kHz}$ & Current controller proportional gain $\left(K_{p c}\right)$ & 10.5 \\
Filter inductance $\left(L_{f}\right)$ & $1.35 \mathrm{mH}$ & Current controller integral gain $\left(K_{i c}\right)$ & $16 \mathrm{e} 3$ \\
Filter capacitance $\left(C_{f}\right)$ & $50 \mu \mathrm{F}$ & Filter cut-off frequency $\left(\omega_{c}\right)$ & $31.4 \mathrm{r} / \mathrm{s}$ \\
Coupling inductance $\left(L_{c}\right)$ & $0.35 \mathrm{mH}$ & Nominal Voltage $\left(V_{n}\right)$ & 380 \\
Line reactance $\left(X_{\text {line }}\right)$ & $0.10 \Omega$ & Nominal Frequency $\left(\omega_{n}\right)$ & $314 r / s$ \\
Line resistance $\left(R_{\text {line }}\right)$ & $0.45 \Omega$ & Droop Gain $\left(m_{p}\right)$ & $9.4 \mathrm{e}-5$ \\
Voltage controller proportional gain $\left(K_{p v}\right)$ & 0.05 & Droop Gain $\left(n_{q}\right)$ & $1.3 \mathrm{e}-3$ \\
Voltage controller integral gain $\left(K_{i v}\right)$ & 390 & Filter resistance $\left(r_{L C}\right)$ & $0.03 \Omega$ \\
Feed forward term $(F)$ & 0.75 & Inverter input resistance $\left(r_{f}\right)$ & $0.1 \Omega$ \\
\hline
\end{tabular}


The DG VSIs controller separated into three parts. First is the outer power controller, which gives the magnitude of voltage and frequency for the VSI output voltage's fundamental component according to the droop characteristics set for the real and reactive power [12]. The other parts of the control systems are the voltage controller and the current controller; these designed to nullify high-frequency noise and provide enough damping for the LC filter [13].

\subsection{Power controller}

The main reason to use the droop controller is to act as the governor of the synchronous alternator. Generally, in a power system, the frequency decreases as the load on the synchronous alternator increases according to the governor's droop characteristics. This droop principle used in VSI by reducing reference frequency and voltage when the load increases, as shown in Figure 2 (a) [14]. Similarly, the output voltage drops as the reactive power on the synchronous alternator increases according to the droop characteristics, called a droop controller, as shown in Figure 2 (b). To calculate power given by (1) and (2), from the inverter output terminal, which is the output voltage and current measured.
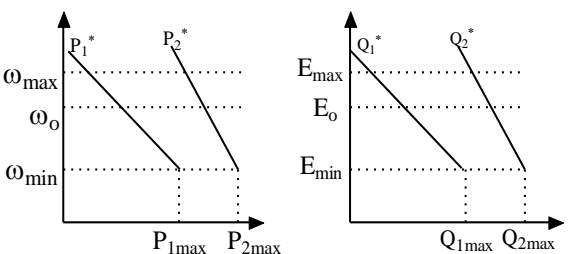

(a)

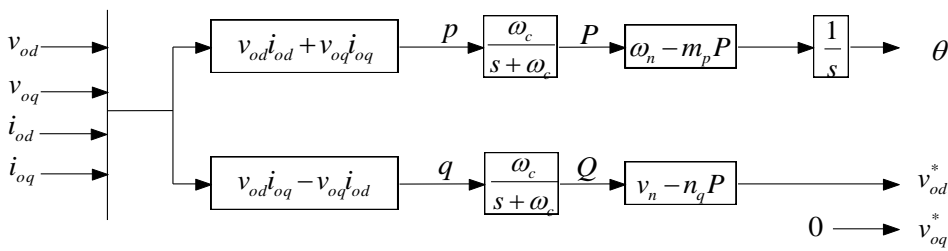

(b)

Figure 2. Power controller, (a) Conventional droop characteristics, (b) Power controller

$$
p=v_{o d} i_{o d}+v_{o q} i_{o q} ; q=-v_{o d} i_{o q}+v_{o q} i_{o d}
$$

The component of active and reactive power obtained by low pass filter with a cut-off frequency $\omega_{c}$, given as:

$$
P=\frac{\omega_{c}}{s+\omega_{c}} p ; Q=\frac{\omega_{c}}{s+\omega_{c}} q
$$

The VSI uses the P and Q droop method expressed in (3) and (4).

$$
\begin{aligned}
& \omega=\omega_{n}-m_{p} P \\
& v_{o d}^{*}=v_{n}-n_{p} Q ; v_{o q}^{*}=0
\end{aligned}
$$

Droop parameters $m_{p}$ and $n_{q}$ are expressed as:

$$
m_{p}=\frac{\omega_{\max }-\omega_{\min }}{P_{\max }} ; n_{p}=\frac{E_{\max }-E_{\min }}{Q_{\max }}
$$

\subsection{Virtual-impedance control}

The VSI network parameters can be affected when droop control implemented, which affects the power-sharing accuracy. To improve this virtual impedance controller is applied [15]. Besides, its use eliminates the circulation of the current. The expression of the output-voltage reference given as:

$$
v_{d q}^{*}=v_{d q, r e f}-Z_{V}(s) i_{d q}
$$

where $\mathrm{Zv}(\mathrm{s})$ is the virtual-output impedance. 


\subsection{Voltage controller}

The voltage control loop, as shown in Figure 3, connected to an inverter current control controller. This control loop used to regulate the inverter voltage output-the reference voltage output set in the power control loop. To make steady-state error zero between the measured and reference voltage, a standard PI controller is responsible. To act controller fast, a feed-forward gain added in the controller. The voltage control loop gives internal current control reference. To regulate the load current of inverter, the internal PI controller protects the VSI switches.

$$
\begin{aligned}
& \frac{d \phi_{d}}{d t}=v_{o d}^{*}-v_{o d} ; \frac{d \phi_{q}}{d t}=v_{o q}^{*}-v_{o q} \\
& i_{l d}^{*}=F i_{o d}-w_{n} C_{f} v_{o q}+K_{p v}\left(v_{o d}^{*}-v_{o d}\right)+K_{i v} \phi_{d} \\
& i_{l q}^{*}=F i_{o q}-w_{n} C_{f} v_{o d}+K_{p v}\left(v_{o q}^{*}-v_{o q}\right)+K_{i v} \phi_{q}
\end{aligned}
$$

\subsection{Current controller}

The Current controller block diagram, as shown in Figure 4. It is the fast-acting control loop of a VSI. Besides, VSI current not to exceed set current reference value a Proportional and Integral controller used. The voltage controller sets the reference value to this controller-the governing equations expressed by (10), (11), and (12). For tuning the CCL and VCL, integral and proportional gain a transfer function approach studied [16].

$$
\begin{aligned}
& \frac{d \gamma_{d}}{d t}=i_{l d}^{*}-i_{l d} ; \frac{d \gamma_{q}}{d t}=i_{l q}^{*}-i_{l q} \\
& v_{l d}^{*}=-w_{n} L_{f} i_{l q}+K_{p c}\left(i_{l d}^{*}-i_{l d}\right)+K_{i c} \gamma_{d} \\
& v_{l q}^{*}=w_{n} L_{f} i_{l d}+K_{p c}\left(i_{l q}^{*}-i_{l q}\right)+K_{i c} \gamma_{q}
\end{aligned}
$$

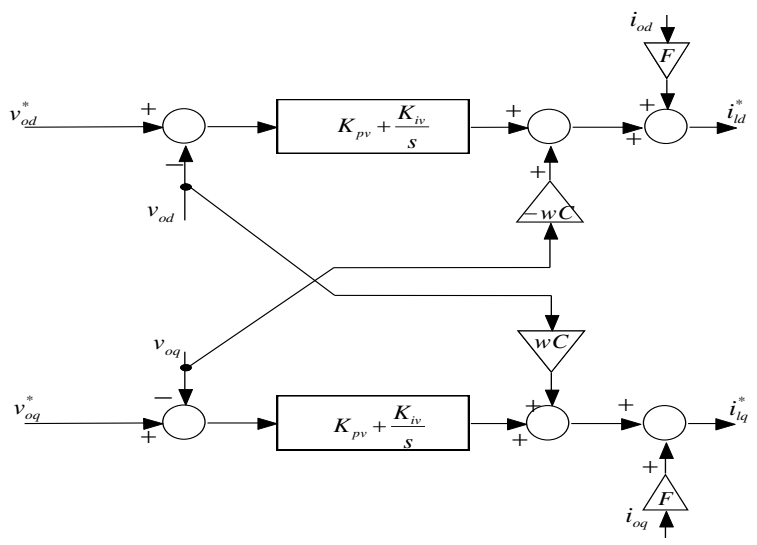

Figure 3. Voltage controller

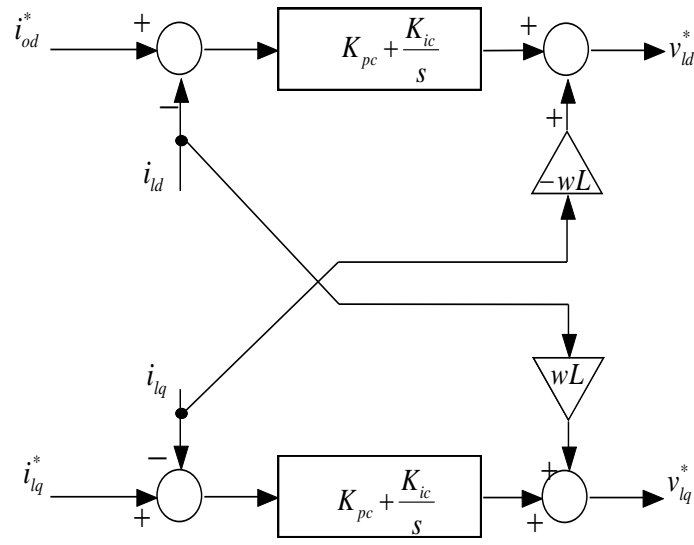

Figure 4. Current controller

\section{STAND ALONE MODELING OF THREE-PHASE VSI}

In standalone system 3-phase, VSIs connected to the network. The power-processing unit is a 3-leg inverter, inductor and capacitor filter, and its ESR, coupling inductor, the DGs input to the VSI, and the voltage given to the loads. The switching frequency is $4-10 \mathrm{kHz}$ of pulse-width modulation (PWM) mechanism. The $L$ and $C$ values need to choose as per inverter rating and the maximum permissible ripples of voltage and current. The differential equations describing dynamics of the VSI can derive as:

$$
v_{i_{-} a b c}=r i_{L_{-} a b c}+L \frac{d i_{L_{-} a b c}}{d t}+v_{C_{-} a b c}
$$




$$
i_{L_{-} a b c}=C \frac{d v_{C_{-} a b c}}{d t}+i_{o_{-} a b c}
$$

where $v_{i_{-} a b c}$ is the line voltage of the inverter, $\boldsymbol{i}_{L_{-} a b c}$ is the inductor line current, $\boldsymbol{v}_{C_{-} a b c}$ is the line voltage of the capacitor, and $\boldsymbol{i}_{o_{-} a b c}$ is the load current. Obtained to rotating from stationary quantity by the transformation matrix. Assuming symmetrical three-phase, transforming (13)-(14) to the rotating frame results in:

$$
\begin{gathered}
L \frac{d}{d t}\left[\begin{array}{c}
I_{l d}^{*} \\
I_{l q}^{*}
\end{array}\right]=\left[\begin{array}{cc}
-r & w L \\
-w L & -r
\end{array}\right]\left[\begin{array}{c}
I_{l d}^{*} \\
I_{l q}^{*}
\end{array}\right]+\left[\begin{array}{c}
V_{o d}^{*}-V_{o d} \\
V_{o q}^{*}-V_{o q}
\end{array}\right] \\
C \frac{d}{d t}\left[\begin{array}{l}
V_{o d} \\
V_{o q}
\end{array}\right]=\left[\begin{array}{c}
C w V_{o q} \\
-C w V_{o d}
\end{array}\right]+\left[\begin{array}{c}
I_{l d}^{*} \\
I_{l q}^{*}
\end{array}\right]-\left[\begin{array}{c}
I_{l d} \\
I_{l q}
\end{array}\right]
\end{gathered}
$$

Rearranging (15)-(16) applying the Laplace transformation, gives:

$$
\begin{aligned}
& {\left[\begin{array}{c}
I_{l d}^{*} \\
I_{l q}^{*}
\end{array}\right]=\frac{1}{L s+r}\left[\begin{array}{c}
V_{o d}^{*}-V_{o d} \\
V_{o q}^{*}-V_{o q}
\end{array}\right]+\frac{1}{L s+r}\left[\begin{array}{c}
(w L) I_{l q}^{*} \\
-(w L) I_{l d}^{*}
\end{array}\right]} \\
& {\left[\begin{array}{c}
V_{o d} \\
V_{o q}
\end{array}\right]=\frac{1}{C s}\left[\begin{array}{c}
C w V_{o q} \\
-C w V_{o d}
\end{array}\right]+\frac{1}{C s}\left[\begin{array}{c}
I_{l d}^{*}-I_{l d} \\
I_{l q}^{*}-I_{l q}
\end{array}\right]}
\end{aligned}
$$

The linearized model of the inverter system, as shown in Figure 5. The equation (17)-(18) consists of the coupling disturbance that exists between $d q$-axis loops; thus, decoupled to remove the interference, as shown in Figures 3 and 4. to enhance the performance of the VSI system [17, 18].

\subsection{Current controller analysis and design}

The performance of the system can improve by giving attention to the inverter controller. So, by using PI controllers, they can be effectively controlled. The disturbances to be more specific, given in (17), $\left(+L_{\omega} I_{l q}\right)$, and $\left(-L_{\omega} I_{l d}\right)$ for the d $q$-axis CCL; opposite parameters are added to the CCL controller to eliminate it. According to the transfer functions, $G_{i d}(s)$ and $G_{i q}(s)$ for the $d q$-axis current control loop derived as:

$$
G_{i d}(S)=G_{i q}(S)=G_{i}(S)=\frac{K_{p c} S+K_{i c}}{L S^{2}+\left(r+K_{p c}\right) S+K_{i c}}
$$

where Kpc and Kic are the proportional and integral gains of the PI controller, respectively. In designing the CCL, the response speed, stability, and harmonics need to consider. To act fast, the bandwidth of CCL should be high [19]. The proportional gain relationship with the CCL bandwidth, using (20), expressed as:

$$
K_{p c}=r+\sqrt{r^{2}+\left(L \omega_{b i}\right)^{2}}
$$

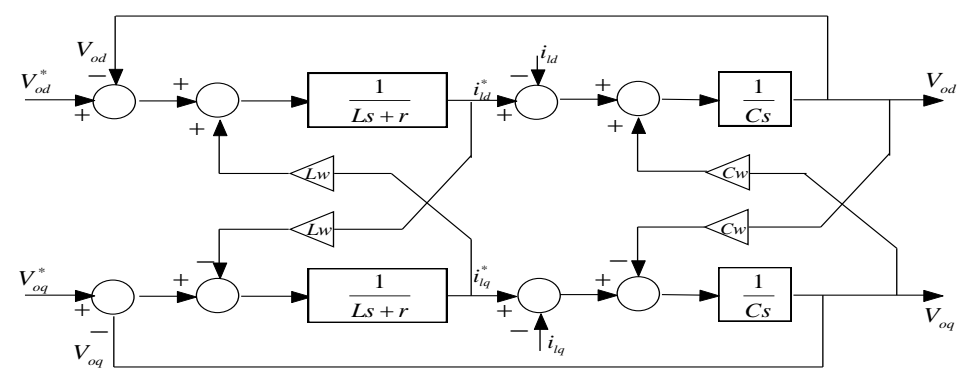

Figure 5. The linearized model of the inverter system and filter output in dq reference frame 
Where $\omega_{b i}$ is the bandwidth of the current controller. Even though many works, not included an integral controller in the CCL [20,21], in abnormal situations, the presence of an integral controller can be beneficial. Although it reduces tracking error (ideally zero) without compromising its dynamic response. Figure 6 (a) shows the Bode plot for the CCL transfer function and Figure 6 (b). Trajectories of CCL closedloop poles

\subsection{Analysis and design of the voltage controller}

The output voltage of VSI should be stable and regulated as per the device's concern. The VCL disturbances given in (18), are $\left(+C_{\omega} V_{o q}\right)$ and $\left(-I_{l d}\right)$ are from the $d$-axis and $\left(-C_{\omega} V_{o d}\right)$ and $\left(-I_{o q}\right)$ are from the $q$-axis. These disturbances have eliminated by adding these terms with the proper signs. The $d$-axis VCL transfer function (21) is $G_{v d}(s)=\left(V_{o d}(s) / V^{*}{ }_{o d}(s)\right) V_{o q}=0, I_{o d}=0$. Note that $G_{V \mathrm{q}}(s)=G_{V \mathrm{~d}}(s)$. The current controller should be faster than the voltage controller for that bandwidth is chosen in the range of 0.25 and 0.75 of $\omega_{b i}$, also greater than ten times of fundamental and greater than cut-off filter frequency [22, 23]. The proportional coefficient has obtained using (22). The voltage transfer function expressed as:

$$
G_{V d}(S)=\frac{V_{C d}}{V_{C d}^{*}}=\frac{K_{p c} K_{p v} S^{2}+\left(K_{p c} K_{p v}+K_{p p} K_{i c}\right)+K_{i c} K_{i v}}{L C S^{4}+C\left(r+K_{p c}\right) S^{3}+\left(K_{p c} K_{p v}+C K_{i c}\right) S^{2}+\left(K_{p c} K_{p v}+K_{p v} K_{i c}\right) S+K_{i c} K_{i v}}
$$

while designing integral gain $\left(K_{i v}\right)$ is a trade-off required between the error and stability of the system. Figure 6 (c) shows the Bode plot for the VCL. The closed-loop poles trajectories using (18), is shown in Figure 6 (d).

$$
\left|G_{v}\left(j w_{b v}\right) \cdot\right|=0.707 \Rightarrow K_{p v}=\frac{C w_{b i}\left(\sqrt{\left.2\left(L w_{b v}\right)^{2}+\left(K_{p c}\right)^{2}\right)-L w_{b i}}\right)}{K_{p c}}
$$

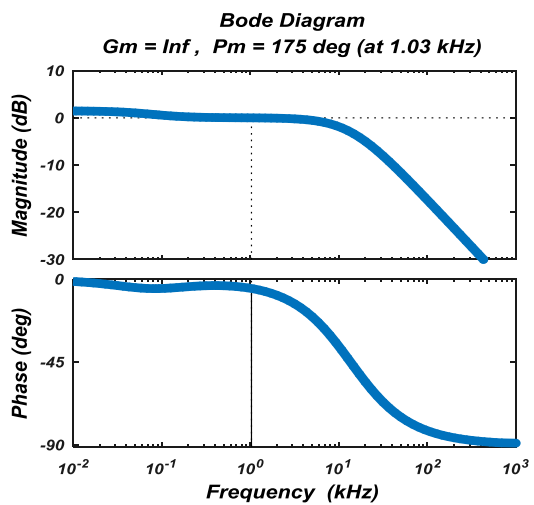

(a)

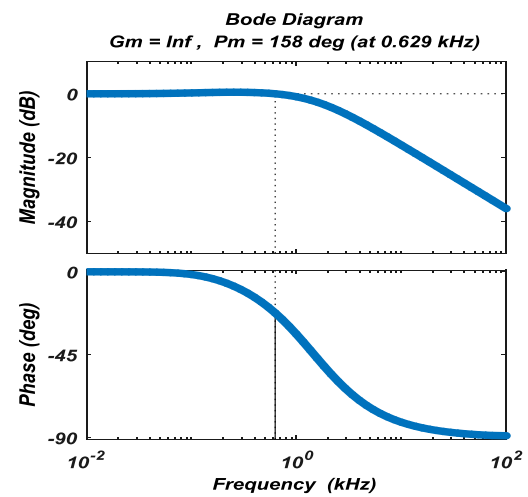

(c)

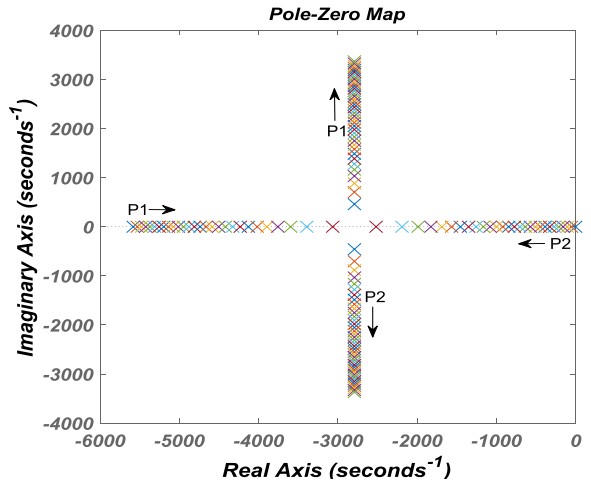

(b)

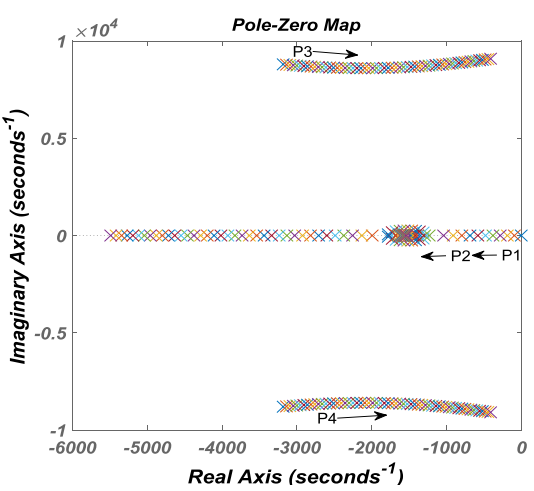

(d)

Figure 6. VCL, (a) Bode plot for CCL transfer function, (b) Trajectories of CCL closed-loop poles, (c) Bode plot with ideal CCL for VCL transfer function, (d) Trajectories of VCL closed-loop poles 


\section{RESULTS AND DISCUSSION}

In this paper, the effectiveness of the proposed droop controller studied in different cases, with nonlinear loads simulated on MATLAB/Simulink tool. To this aim, the test bench used as standalone DG. This system has two parallel VSI and its controller with network impedance, as shown in Figure 1 (a). Two DG VSIs connected in parallel, and droop gain and network impedance considered as given in Table 1.

Three following cases discussed and shown in Figures 7 and 8. Case 1: At $\mathrm{t}=0$ to $0.7 \mathrm{~s}$, a total load of $\mathrm{P}_{\mathrm{Load}}=16000 \mathrm{~W}$ and $\mathrm{Q}_{\mathrm{Load}}=8000 \mathrm{VAR}$ are connected, and each inverter is sharing the load proportionally, i.e., the active power of $\mathrm{P}_{1}=7570 \mathrm{~W}$ and $\mathrm{P}_{2}=7560 \mathrm{~W}$, and reactive power of $\mathrm{Q}_{1}=3823.5 \mathrm{VAR}$ and $\mathrm{Q}_{2}=3823$ VAR at $0.43 \mathrm{~s}$, as shown in Figure 7 (a) and 7 (b), similarly Case 2: At t $=0.7 \mathrm{~s}$ to $1.2 \mathrm{~s}$ change in load of $\mathrm{P}_{\text {Load }}=12000 \mathrm{~W}$ and $\mathrm{Q}_{\text {Load }}=10000 \mathrm{VAR}$ added into the microgrid system, and each inverter is sharing the load proportionally, i.e., $\mathrm{P}_{1}=5677 \mathrm{~W}$ and $\mathrm{P}_{2}=5766 \mathrm{~W}$ and reactive power of $\mathrm{Q}_{1}=4754 \mathrm{VAR}$ and $\mathrm{Q}_{2}=4753.5 .1$ VAR. Case 3: At $\mathrm{t}=1.2$ to $2 \mathrm{~s}$ change in a load of $\mathrm{P}_{\mathrm{Load}}=10000 \mathrm{~W}$ and $\mathrm{Q}_{\mathrm{Load}}=8000 \mathrm{VAR}$ is added into the microgrid system, and each inverter is sharing the load proportionally, i.e., $\mathrm{P}_{1}=4750 \mathrm{~W}$ and $\mathrm{P}_{2}=4740 \mathrm{~W}$ and reactive power of $\mathrm{Q}_{1}=3823.5 \mathrm{VAR}$ and $\mathrm{Q}_{2}=3823 \mathrm{VAR}$.

Thus in all cases, the frequency variation of inverters is within the tolerance range, and at $0.48 \mathrm{~s}$, the frequency variation is $49.8869 \mathrm{~Hz}$ to $49.8868 \mathrm{~Hz}$ due to load change, as shown in Figure 7 (c). The DG1 and DG2 output voltage obtained of $780 \mathrm{Vdc}$ as sources, as shown in Figures 7 (d) and Figure 8 (a), to feed each inverter. The point of common coupling voltage is 220 volts/phase (RMS) at each load, as shown in Figure 8 (b). Also, the voltage at the point of common coupling Vb1 and Vb2 per-phase-voltage (Vpeak) maintained constant irrespective of load variation. Thus, the droop controller is ensuring the tolerances are not more than $5 \%$ and $1 \%$ of voltage and frequency, respectively. The total harmonic distortion (THD) of voltage is $2.61 \%$ when the nonlinear load has connected shown in Figures 8 (c) and 8 (d). A comparison has drawn between the proposed method and its similar types, which has illustrated in Table 2. It has observed that our controller has the advantage of better features.

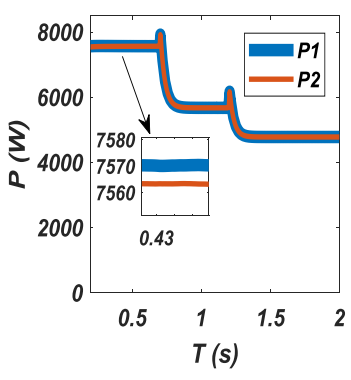

(a)

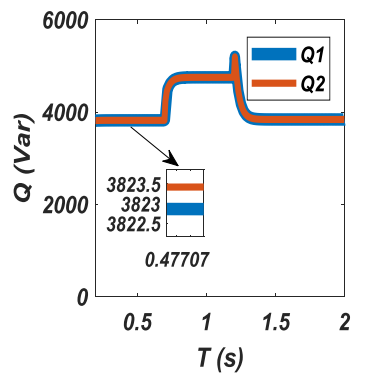

(b)

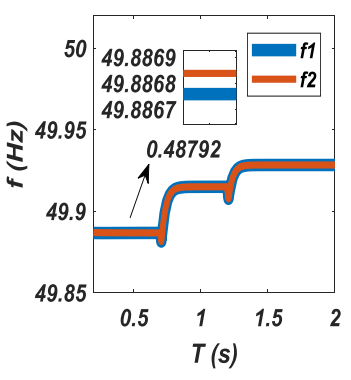

(c)

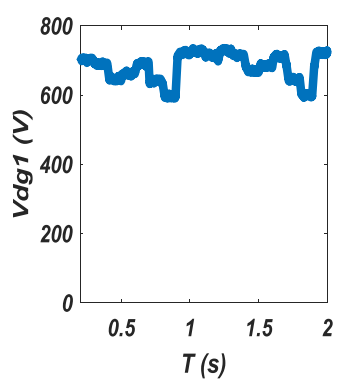

(d)

Figure 7. Case studies, (a) Active power, (b) Reactive power, (c) Frequency with step change load, (d) DG1 o/p voltage

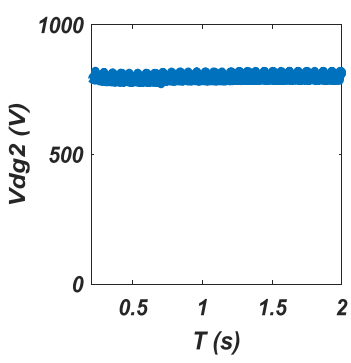

(a)

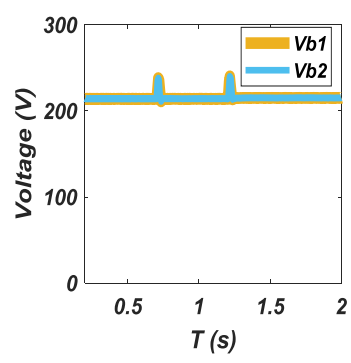

(b)

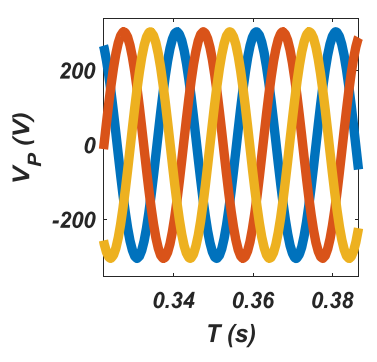

(c)

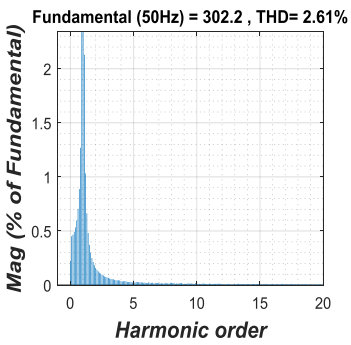

(d)

Figure 8. DG and PCC, (a) DG2 o/p voltage, (b) PCC voltage/ph. (RMS), (c) PCC voltage/ph. (Vpeak), (d) THD of voltage 
Table 2. Comparative analysis of the proposed controller with other existing literature

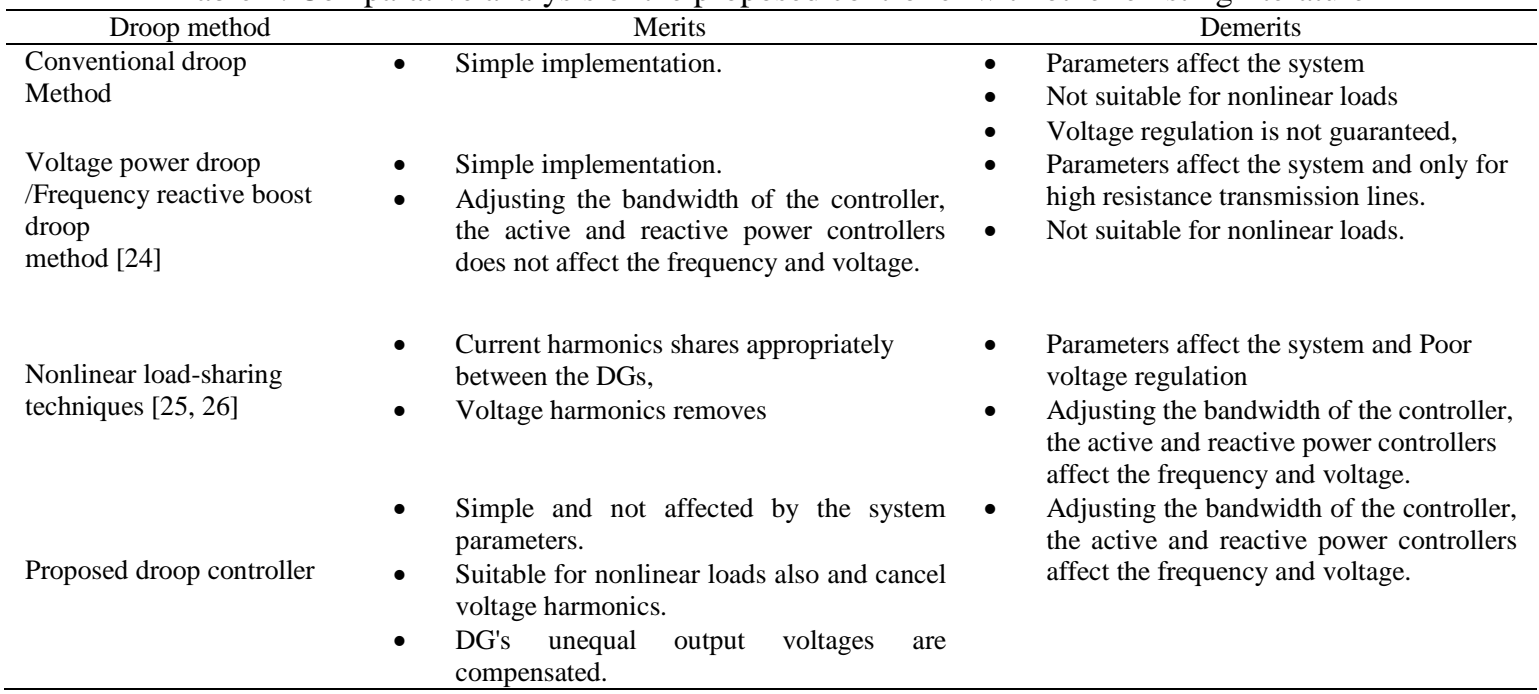

\section{CONCLUSION}

In this paper, the given droop controller proposed in an autonomous parallel inverter-based microgrid system shares power very precisely by avoiding communication link for an islanded microgrid. The proposed control scheme has implemented based on current control and voltage control loop; thus, it can efficiently maintain the frequency and voltage magnitude of the inverters and achieve effective, proportional load sharing of active and reactive power. The implemented controller effectiveness tested on the parallel standalone system of three-phase voltage source inverters with a filter output feeding to the loads.

\section{REFERENCES}

[1] T. Strasser et al., "A Review of Architectures and Concepts for Intelligence in Future Electric Energy Systems," in IEEE Transactions on Industrial Electronics, vol. 62, no. 4, pp. 2424-2438, 2015.

[2] N. L. Díaz, J. C. Vasquez and J. M. Guerrero, "A Communication-Less Distributed Control Architecture for Islanded Microgrids With Renewable Generation and Storage," in IEEE Transactions on Power Electronics, vol. 33, no. 3, pp. 1922-1939, 2018.

[3] S. Riverso, F. Sarzo and G. Ferrari-Trecate, "Plug-and-Play Voltage and Frequency Control of Islanded Microgrids With Meshed Topology," in IEEE Transactions on Smart Grid, vol. 6, no. 3, pp. 1176-1184, 2015.

[4] A. Yazdani and P. P. Dash, "A Control Methodology and Characterization of Dynamics for a Photovoltaic (PV) System Interfaced With a Distribution Network," in IEEE Transactions on Power Delivery, vol. 24, no. 3, pp. 1538-1551, 2009.

[5] R. Teodorescu, F. Blaabjerg, M. Liserre and P. C. Loh, "Proportional-resonant controllers and filters for grid-connected voltage-source converters," in IEE Proceedings - Electric Power Applications, vol. 153, no. 5, pp. 750-762, 2006.

[6] J. C. Vasquez, J. M. Guerrero, J. Miret, M. Castilla and L. G. de Vicuña, "Hierarchical Control of Intelligent Microgrids," in IEEE Industrial Electronics Magazine, vol. 4, no. 4, pp. 23-29, 2010.

[7] J. M. Guerrero, M. Chandorkar, T. Lee and P. C. Loh, "Advanced Control Architectures for Intelligent Microgrids-Part I: Decentralized and Hierarchical Control," in IEEE Transactions on Industrial Electronics, vol. 60, no. 4, pp. 1254-1262, 2013.

[8] X. Zhao, J. M. Guerrero, M. Savaghebi, J. C. Vasquez, X. Wu and K. Sun, "Low-Voltage Ride-Through Operation of Power Converters in Grid-Interactive Microgrids by Using Negative-Sequence Droop Control," in IEEE Transactions on Power Electronics, vol. 32, no. 4, pp. 3128-3142, 2017.

[9] R. R. Kolluri, I. Mareels, T. Alpcan, M. Brazil, J. de Hoog and D. A. Thomas, "Power Sharing in Angle Droop Controlled Microgrids," in IEEE Transactions on Power Systems, vol. 32, no. 6, pp. 4743-4751, 2017.

[10] Y. Guan, J. M. Guerrero, X. Zhao and J. C. Vasquez, "Comparison of a synchronous reference frame virtual impedance-based autonomous current sharing control with conventional droop control for parallel-connected inverters," 2016 IEEE 8th International Power Electronics and Motion Control Conference (IPEMC-ECCE Asia), Hefei, pp. 3419-3426, 2016.

[11] M. C. Chandorkar, D. M. Divan and R. Adapa, "Control of parallel connected inverters in standalone AC supply systems," in IEEE Transactions on Industry Applications, vol. 29, no. 1, pp. 136-143, 1993.

[12] B. Bahrani, S. Kenzelmann and A. Rufer, "Multivariable-PI-Based \$dq \$ Current Control of Voltage Source Converters With Superior Axis Decoupling Capability," in IEEE Transactions on Industrial Electronics, vol. 58, no. 7, pp. 3016-3026, 2011.

[13] B. Bahrani, A. Karimi, B. Rey and A. Rufer, "Decoupled dq-Current Control of Grid-Tied Voltage Source Converters Using Nonparametric Models," in IEEE Transactions on Industrial Electronics, vol. 60, no. 4, pp. 1356-1366, 2013.

[14] N. Pogaku, M. Prodanovic and T. C. Green, "Modeling, Analysis and Testing of Autonomous Operation of an Inverter-Based Microgrid," in IEEE Transactions on Power Electronics, vol. 22, no. 2, pp. 613-625, 2007. 
[15] Y. Sun, X. Hou, J. Yang, H. Han, M. Su and J. M. Guerrero, "New Perspectives on Droop Control in AC Microgrid," in IEEE Transactions on Industrial Electronics, vol. 64, no. 7, pp. 5741-5745, 2017.

[16] M. N. Marwali and A. Keyhani, "Control of distributed generation systems-Part I: Voltages and currents control," in IEEE Transactions on Power Electronics, vol. 19, no. 6, pp. 1541-1550, 2004.

[17] M. Ramezani, S. Li and S. Golestan, "Analysis and controller design for stand-alone VSIs in synchronous reference frame," in IET Power Electronics, vol. 10, no. 9, pp. 1003-1012, 2872017.

[18] M. N. Marwali, Jin-Woo Jung and A. Keyhani, "Control of distributed generation systems - Part II: Load sharing control," in IEEE Transactions on Power Electronics, vol. 19, no. 6, pp. 1551-1561, 2004,.

[19] Q. Zhong and T. Hornik, "Cascaded Current-Voltage Control to Improve the Power Quality for a Grid-Connected Inverter With a Local Load," in IEEE Transactions on Industrial Electronics, vol. 60, no. 4, pp. 1344-1355, 2013.

[20] M. Monfared, S. Golestan and J. M. Guerrero, "Analysis, Design, and Experimental Verification of a Synchronous Reference Frame Voltage Control for Single-Phase Inverters," in IEEE Transactions on Industrial Electronics, vol. 61, no. 1, pp. 258-269, 2014.

[21] S. S. Thale, R. G. Wandhare and V. Agarwal, "A Novel Reconfigurable Microgrid Architecture With Renewable Energy Sources and Storage," in IEEE Transactions on Industry Applications, vol. 51, no. 2, pp. 1805-1816, 2015.

[22] J. He, Y. W. Li and F. Blaabjerg, "An Enhanced Islanding Microgrid Reactive Power, Imbalance Power, and Harmonic Power Sharing Scheme," in IEEE Transactions on Power Electronics, vol. 30, no. 6, pp. 3389-3401, 2015.

[23] C. K. Sao and P. W. Lehn, "Control and Power Management of Converter Fed Microgrids," in IEEE Transactions on Power Systems, vol. 23, no. 3, pp. 1088-1098, 2008.

[24] U. Borup, F. Blaabjerg and P. N. Enjeti, "Sharing of nonlinear load in parallel-connected three-phase converters," in IEEE Transactions on Industry Applications, vol. 37, no. 6, pp. 1817-1823, 2001.

[25] A. Firdaus and S. Mishra, "A double derivative based droop controller for improved power sharing in inverter based autonomous microgrid," 2018 IEEMA Engineer Infinite Conference (eTechNxT), New Delhi, pp. 1-6, 2018.

[26] A. Bidram, V. Nasirian, A. Davoudi and F. L. Lewis, "Cooperative synchronization in distributed microgrid control," Switzerland: Springer, 2017.

\section{BIOGRAPHIES OF AUTHORS}
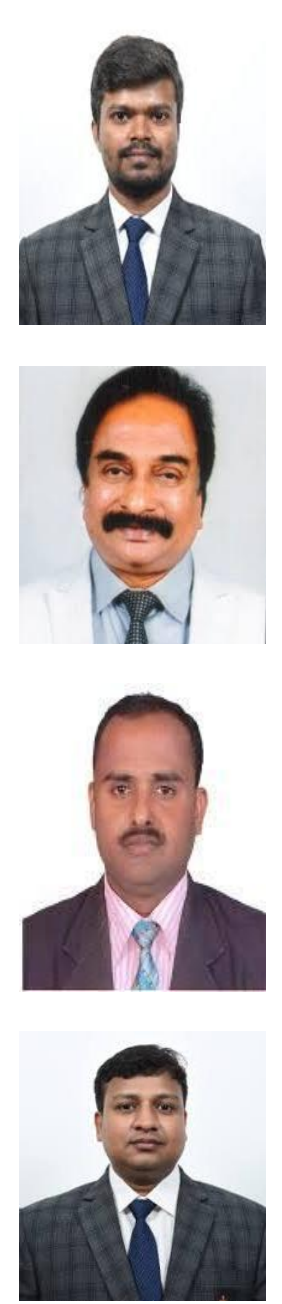

Siddaraj is an assistant professor in the Department of Electrical and Electronics Engineering, Manipal Institute of Technology, Manipal Academy of Higher Education, Manipal. Currently, pursuing a PhD in the Department of Electrical Engineering, NITK Surathkal. He has authored several research articles in journals and conferences. His research field includes renewable energy sources microgrids, power and energy systems.

Udaykumar R. Yaragatti is currently a professor (on-lien) heading the Malaviya National Institute of Technology Jaipur, Jaipur, India, as the director since October 2016. He is the author of more than 90 published technical papers, and the co-author of chapters 3, 4, and 5 in Thermal Power Plants: Modeling, Control, and Efficiency Improvement (CRC Press, 2016). His research interests include power electronic converters, photovoltaics, smart grid, energy management, and electric drives.

Nagendrappa H received the B.E. degree in electrical and electronics engineering, in 1999, the M.Tech. degree in power and energy systems, in 2002, both from the National Institute of Technology Karnataka (NITK), Surathkal, India, and the Ph.D. degree in electrical engineering in 2015 from the University of Victoria, Victoria, BC, Canada. He has been an assistant professor in the Department of Electrical Engineering, NITK Surathkal. He is interested in working on high-frequency soft-switching converters for power generation from renewable energy sources and their grid interfacing applications.

Vikash Kumar Jhunjhunwala is an assistant professor in the Department of Electrical and Electronics Engineering, Manipal Institute of Technology, Manipal Academy of Higher Education, Manipal. He has authored several research articles in journals and conferences. His research field includes renewable energy sources microgrids, power, and energy systems. 